\title{
Effects of Symmetry on Circular and Linear Magnetic Dichroism in Angle-Resolved Photoemission Spectra of $\mathrm{Gd} / \mathrm{Y}(0001)$ and $\mathrm{Fe}-\mathrm{Ni} / \mathrm{Cu}(001)$
}

K. W. Goodman, J. G. Tobin, F. O. Schumann,

R. F. Willis, J. W. Gammon, D. P. Pappas,

J. B. Kortright, J. D. Denlinger, E. Rotenberg, A. Warwick, N. V. Smith

This paper was prepared for submittal to the 1997 Spring Materials Research Society Meeting Symposium $\mathbf{M}$

San Francisco, CA

March 31-April 4, 1997

March 26, 1997

This is a preprint of a paper intended for publication in a journal or proceedings. Since changes may be made before publication, this preprint is made available with the understanding that it will not be cited or reproduced without the permission of the author. 


\section{DISCLAIMER}

This document was prepared as an account of work sponsored by an agency of the United States Government. Neither the United States Government nor the University of California nor any of their employees, makes any warranty, express or implied, or assumes any legal liability or responsibility for the accuracy, completeness, or usefulness of any information, apparatus, product, or process disclosed, or represents that its use would not infringe privately owned rights. Reference herein to any specific commercial product, process, or service by trade name, trademark, manufacturer, or otherwise, does not necessarily constitute or imply its endorsement, recommendation, or favoring by the United States Government or the University of California. The views and opinions of authors expressed herein do not necessarily state or reflect those of the United States Government or the University of California, and shall not be used for advertising or product endorsement purposes. 
Effects of symmetry on circular and linear magnetic dichroism in angle-resolved photoemission spectra of $G d / Y(0001)$ and $\mathrm{Fe}-\mathrm{Ni} / \mathrm{Cu}(001)$

K. W. Goodman, J. G. Tobin, Lawrence Livermore National Laboratory, Livermore, CA 94551; F. O. Schumann, R. F. Willis, Department of Physics, Pennsylvania State University, University Park, Pennsylvania 16802; J. W. Gammon, D. P. Pappas, Department of Physics, Virginia Commonwealth University, Richmond, Virginia 23284, J. B. Kortright, J. D. Denlinger, E. Rotenberg. A. Warwick and N. V. Smith, Lawrence Berkeley Laboratory, Berkeley, Califomia 94720

We have observed circular and linear magnetic dichroisms in angle-resolved photoemission spectra of 50-monolayer $\mathrm{Gd}$ films grown on $\mathrm{Y}(0001)$ and 6-monolayer $\mathrm{Fe}$ Ni alloy films grown on $\mathrm{Cu}(001)$. The $4 f$ level of $\mathrm{Gd}$ and the $\mathrm{Fe} 3 p$ level of the Fe-Ni alloy were measured. A different geometry was used for the magnetic circular dichroism than was used to measure the magnetic linear dichroism. The geometries were chosen so that the shape of the magnetic circular dichroism is predicted to be equal to the shape of the magnetic linear dichroism for four-fold symmetric $\mathrm{Fe}-\mathrm{Ni} / \mathrm{Cu}(001)$ but not for three-fold symmetric $G d / Y(0001)$. Experimental results are presented.

In this paper we examine the effect of symmetry (experimental geometry and sample symmetry) on magnetic linear and circular dichroism measured in angle-resolved photoemission. In particular we chose separate geometries for measuring magnetic circular and magnetic linear dichroisms. The geometries were chosen such that samples with fourfold symmetry about the sample normal may have magnetic circular and magnetic linear dichroisms of the same shape. But samples with three-fold symmetry should not exhibit circular and magnetic linear dichroisms of the same shape. The samples studied are threefold symmetric Gd films grown on Y(0001) and four-fold symmetric Fe-Ni alloy films grown on $\mathrm{Cu}(001)$. After presenting the methods of the experiment, we briefly review parts of a model of magnetic dichroism developed by Venus and coworkers (Refs. 1 and 2) and our specialization and extension of it, particularly for $\mathrm{FeNi} / \mathrm{Cu}(001)$. (Ref. 3 and 4). We then show the results of our measurements.

All of the photoemission spectra were recorded at the Spectromicroscopy Facility (beamline 7) of the Advanced Light Source at Lawrence Berkeley Laboratory using undulator radiation and a spherical-grating monochromator (Ref. 5). Both circularly- and linearly-polarized light were used. Circularly polarized light was generated with a multilayer acting as a phase-retarder, approximating a quarter-wave plate (Ref. 6 and 7 ). 
Venus and co-workers (Ref. 1 and 2) have developed a model of magnetic dichroism particularly useful for comparing dichroism spectra that are measured with different experimental geometries or with different light polarization, or both. We have refined and extended this model for in-plane magnetization $(\vec{M} \mid \pm \hat{x})$ and normal emission, $(\bar{A} \mid-\hat{z})$ as discussed in Refs. 3 and 4. For $C_{4 v}$ symmetry (i.e., NiFe/Cu(001)) a particularly simple pair of equations can be derived. For the $C_{3 v}$ symmetry of $G d / Y(0001)$. the relationship between circular and linear dichroism will not be so simple or elegant.

Circular $\quad D_{c}^{M}=2\left[P_{c}\right] \cos \theta \operatorname{Imag} \quad\{M|z| b<k|y| M>\} \quad$ (Eq. 1) Linear $\quad D_{L}{ }^{M}=\left[1+P_{L}\right] \cos \theta$ Real $\{<M|z| k>k|y| M>\} \quad$ (Eq. 2)

We performed magnetic dichroism measurements on two systems; three-fold symmetric ( $C_{30}$ about the surface normal) $G d$ films grown on $Y(0001)$ (Ref. 10) and fourfold symmetric $\left(\mathrm{C}_{40}\right) \mathrm{Fe}-\mathrm{Ni}$ films grown on $\mathrm{Cu}(001)$ (Refs. 3 and 4).

The MCD and MLD spectra of Gd/Y(0001) are shown in Figure 1. The difference spectra are illustrated in Figure 2. The MCD and MLD signal do not have the same line shape as can be seen in Fig. 2, where the MLD signal has been multiplied by 4.1 so that the height of the positive peaks in the MCD and MLD signals are equal. Because Gd/(0001) does not have $\mathrm{C}_{40}$ symmetry we expect the MCD and MLD signals to be different, as is observed.
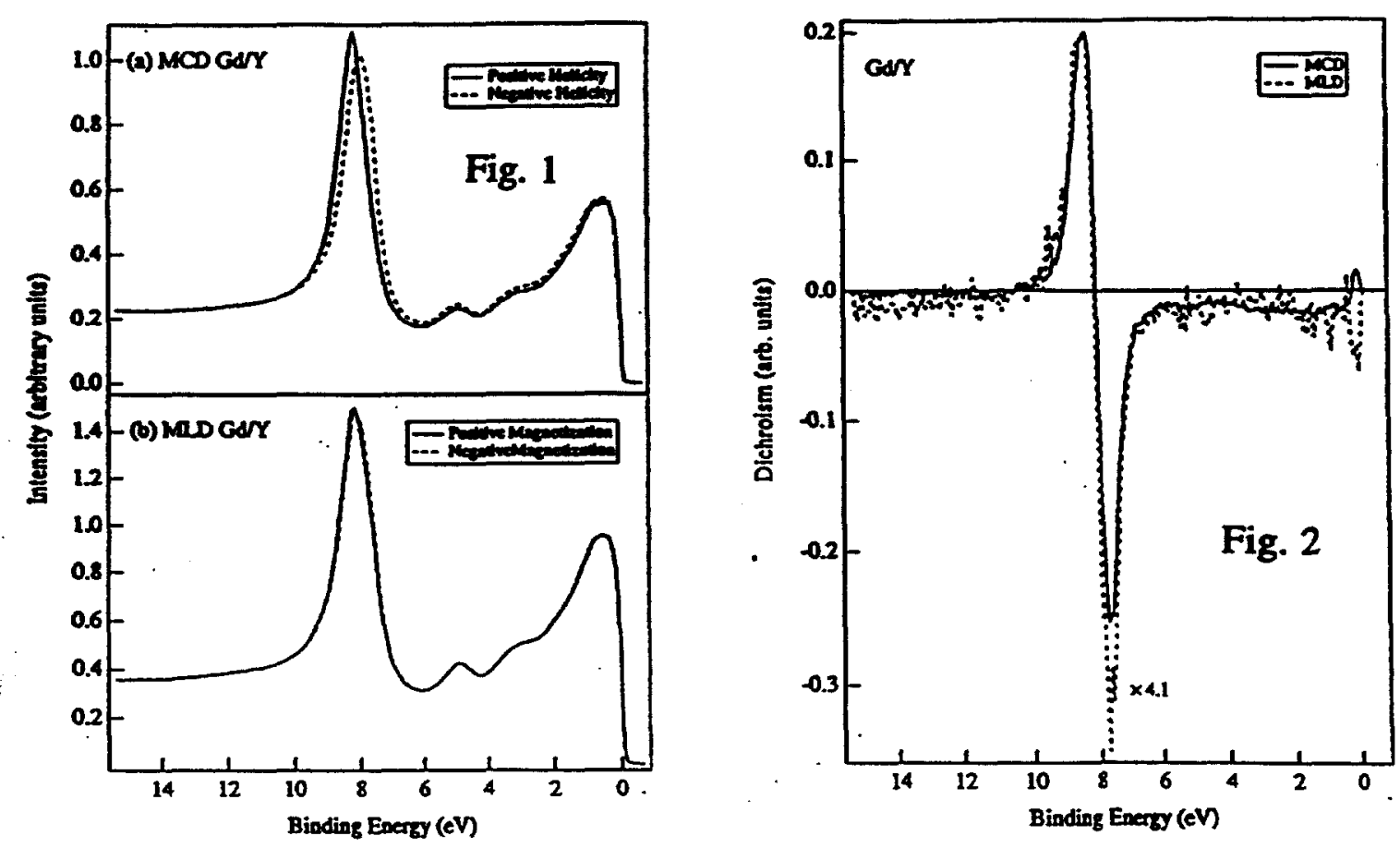
Fig. 1

Magnetic dichroism spectra of the Gd $4 f$ level in Gd grown on Y(0001): (a) magnetic circular dichroism; (b) magnetic linear dichroism. All spectra taken at hv $=95 \mathrm{eV}$.

Fig. 2 Difference spectra of $\mathrm{Gd}$ on $\mathrm{Y}(0001)$ derived from the magnetic dichroism spectra in Fig. 2

The MCD and MLD results for the Fe $3 p$ level of Fe-Ni/Cu(001) are shown in Figure 3. Because $\mathrm{Fe}-\mathrm{Ni} / \mathrm{Cu}(\mathrm{OO1})$ has $\mathrm{C}_{40}$ symmetry, the $\mathrm{MCD}$ and $\mathrm{MLD}$ signals may have the same shape. The inelastic backgrounds were subtracted, using seventh-order polynomials fitted to the first and last $2-\mathrm{eV}$ of each spectrum. The corresponding MCD and MID difference spectra are shown in Fig. 4. Clearly, these are very strongly similar, if not quite identical.
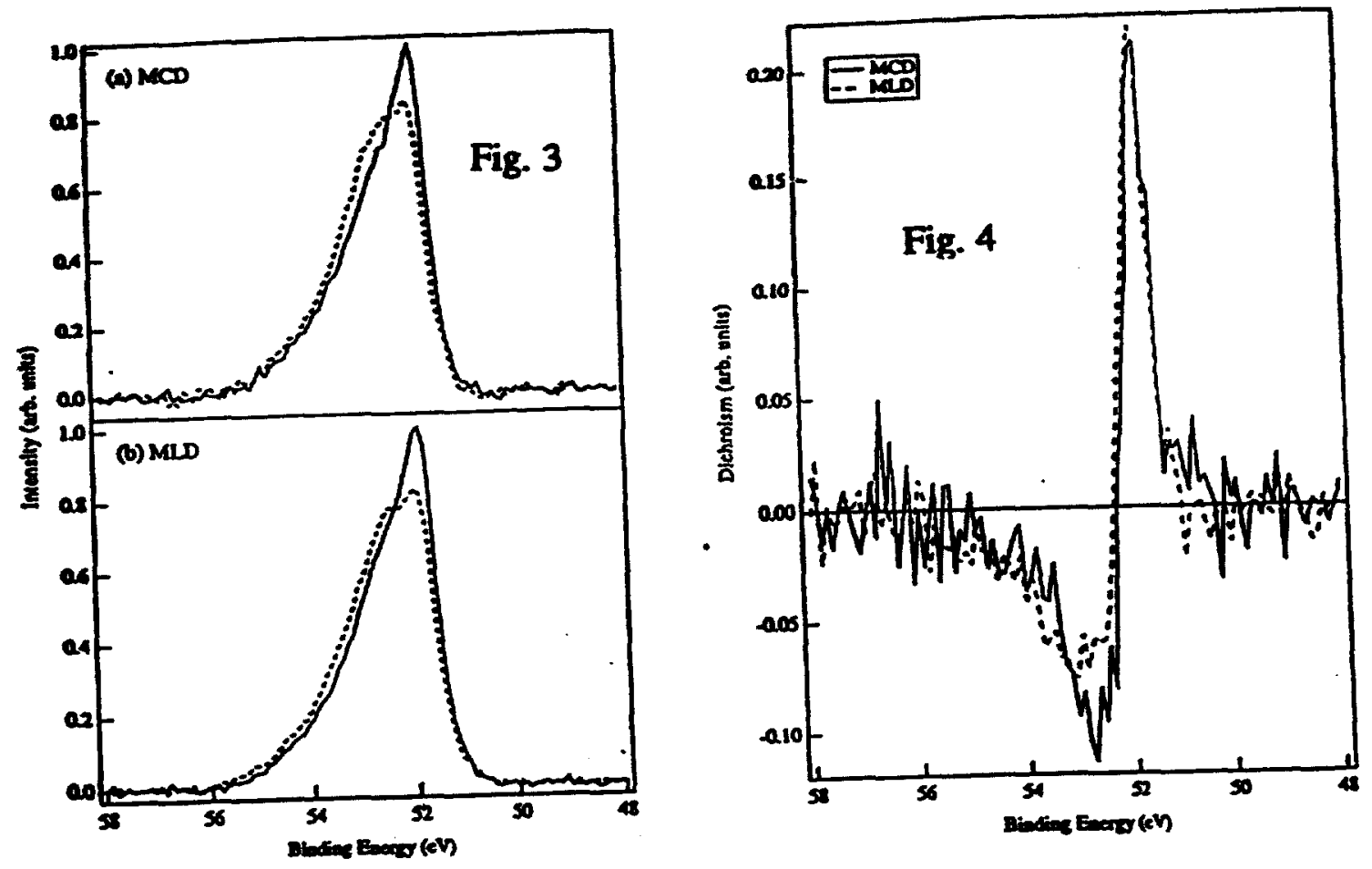

Fig. 3 Magnetic dichroism spectra of the $\mathrm{Fe} 3 p$ level in Fe-Ni grown on $\mathrm{Cu}(001)$. Inelastic backgrounds were subtracted from each spectrum. Then the areas under the $\mathrm{Fe} 3 p$ levels were normalized to a common value.

Fig. 4 (dashed line) of $\mathrm{Fe}-\mathrm{Ni}$ on $\mathrm{Cu}(001)$ shown on a common scale. 
This work was performed under the auspices of the U.S. Department of Energy by Lawnence Livermore National Laboratory under Contract No. E-7405-ENG-48. The Spectromicroscopy Facility and the Advanced Light Source are supported by the U.S. Department of Energy, in particular the Office of Basic Energy Science. It is based in part upon work supported by the National Science Foundation under grand DMR-945 8004. Additional funding from the Research Corporation under grand no. CC 3778 and the Jeffress Trust, No. J338, is also acknowledged.

\section{REFERENCES}

1. D. Venus, Phys. Rev. B 49, 8821 (1994) and references therein.

2. D. Venus, Phys. Rev. B 48, 6144 (1993) and references therein.

3. J. G. Tobin, K. W. Goodman, F. O. Schumann, R. F. Willis, J. B. Kortright, J., Denlinger, E. Rotenberg, A. Warwick, and N. V. Smith, J. Vac. Sci. Technol. 15, May/June 1997

4. J. G. Tobin, K. W. Goodman, G. J. Mankey, R. F. Willis, J. O. Denlinger, E. Rotenberg and A. Warwick, J. Appl. Phys. 79, 5626 (1996) and J. Vac. Sci. Tech., B 14, 3171 (1996).

5. J. D. Denlinger, E. Rotenberg, T. Warwick, G. Visser, J. Nordgren, J. H. Guo, P. Skytt, S. D. Kevan, K. S. McCutcheon, D. Shuh, J. Bucher, N. Edelstein, J. G. Tobin, and B. P. Tonner, Rev. Sci. Instrum. 66, 1342 (1995).

6. The phase retarder is a slight variant of that described in the following paper: J. B. Kortright, M. Rice and K. D. Franck, Rev. Sci. Instrum. 66, 1567 (1995).

7. J. B. Kortright, H. Kimura, V. Nikitin, K. Mayama, M. Yamamoto, and M. Yanagihara, Appl. Phys. Lett 60, 2963 (1992); J. B. Kortright and J. H. Underwood, Nucl. Instrum. and Methods A291, 272 (1990).

8. Physical Electronics Model 10-360 Spherical Capacitor Analyzer.

9. The energy resolution was determined by Ar 3p gas phase measurements: E. Rotenberg and J. D. Denlinger (private communication).

10. W. J. Gammon, S. R. Mishra, D. P. Pappas, K. W. Goodman, J. G. Tobin, F. O. Schumann, R. Willis, J. D. Denlinger, E. Rotenberg, A. Warwick, and N. U. Smith, J. Vac. Sci. Tech., A 15, May/June (1997). 


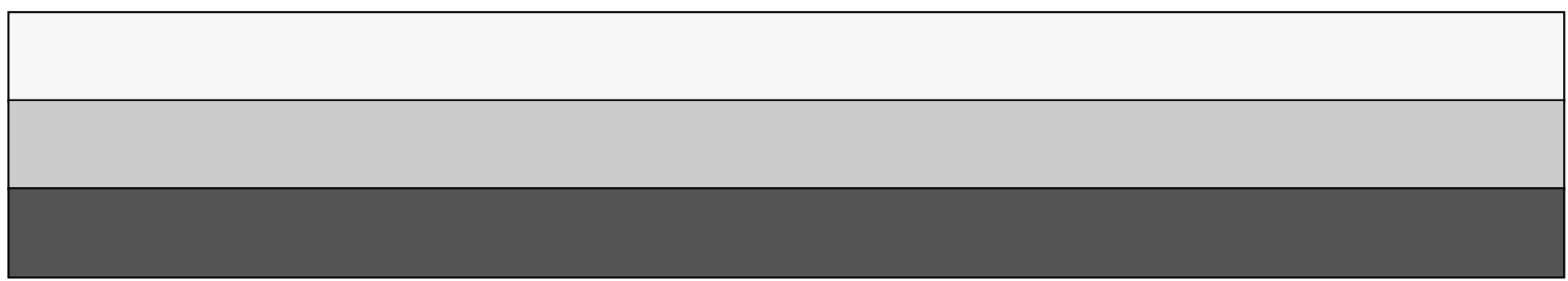

